\title{
Corrosion Inhibition and Adsorption of Anthocleista Djalonesis Leaf Extract on the Acid Corrosion of Mild Steel
}

\author{
C.E. Ogukwe, ${ }^{a}$ C.O. Akalezi, ${ }^{a}$ M. A. Chidiebere, ${ }^{a}$ K.L. Oguzie, ${ }^{b}$ \\ Z.O. Iheabunike, ${ }^{a}$ and E.E. Oguzie ${ }^{a, *}$ \\ ${ }^{a}$ Electrochemistry and Materials Science Research Laboratory, Department of Chemistry, \\ Federal University of Technology Owerri, PMB 1526 Owerri, Nigeria \\ ${ }^{b}$ Department of Environmental Technology, Federal University of Technology Owerri, PMB \\ 1526 Owerri, Nigeria
}

Received 18 January 2012; accepted 30 June 2012

\begin{abstract}
Aqueous extracts of the leaves of Anthocleista djalonesis (AD) have been investigated as non toxic corrosion inhibitors for mild steel in acidic environments $(1 \mathrm{M} \mathrm{HCl}$ and 0.5 $\mathrm{M} \mathrm{H}_{2} \mathrm{SO}_{4}$, respectively). Corrosion rates were evaluated at $30{ }^{\circ} \mathrm{C}$ using the weight loss, electrochemical impedance spectroscopy and potentiodynamic polarization techniques. AD extract was found to inhibit mild steel corrosion in both acidic media via adsorption of the extract organic matter on the metal/solution interface. Polarization data indicate that the extract functioned via a mixed inhibition mechanism, affecting both the cathodic and anodic partial reactions of the corrosion process. Molecular dynamics (MD) simulations were performed to illustrate the adsorption process of some specific components of the extract.
\end{abstract}

Keywords: corrosion inhibition; biomass extract; Anthocleista djalonesis; adsorption; molecular dynamics simulations.

\section{Introduction}

The corrosion of metals by acids is a major dilemma encountered in numerous industrial processes. A significant method to protect the metals from corrosion is the addition of species to the solution in contact with the surface in order to inhibit the corrosion reaction and reduce the corrosion rate. To this end, the use of organic compounds containing nitrogen, oxygen, or sulphur as inhibitors to reduce corrosion attack has received detailed attention [1-11]. These compounds act at the interphase created by the corrosion product between the metal and the

\footnotetext{
* Corresponding author. E-mail: eeoguzie@imr.ac.cn
} 
aqueous aggressive solution, and their interaction with the corroding metal surface, usually via adsorption, often leads to a modification in either the mechanism of the electrochemical process at the double layer or in the surface available to the process.

Owing to increasing ecological awareness and strict environmental regulations, attention is now focusing on the development of substitute environmentally friendly alternatives to hazardous chemical processes. Such development will ultimately rely on the only practical sustainable source of materials - plant (biomass) extracts - and provoke more ingenious utilization of these extracts as sources of alternative benign chemical substances. With this in mind, we have over time investigated the possibility of applying biomass extracts directly in solving materials corrosion problems and as potential replacements for the costly and toxic chemicals in use presently. The key hypothesis here is that some phytochemical constituents of plant extracts including tannins, proteins, polysaccharides, polycarboxylic acids, alkaloids, etc., possess electronic structures akin to those of conventional organic corrosion inhibitors and some have actually been reported to function as inhibitors of metal corrosion [12-20].

The leaf extract Anthocleista djalonesis (AD) has been studied in this work for its inhibiting effect on mild steel corrosion in aqueous acidic environments. The plant is of West African origin and is used extensively in traditional medicine for treatment of various diseases due to its acclaimed antipyretic, stomachic, analgesic and purgative action. Chemical compounds isolated from the leaves include an iridoid glucoside (djalonenoside), which is the major constituent of the plant, a dibenzo- $\alpha$-pyrone (djalonensone), ursolic acid, 3-oxo- $\Delta^{4,5}$-sitosterone, etc. $[21,22]$. Corrosion rates in the absence and presence of the extract have been determined using the gravimetric and electrochemical techniques, while density functional theory (DFT) based quantum chemical computation was employed to model the electronic and adsorption structures of some active components of the extract.

\section{Experimental \\ Materials preparation}

Tests were performed on carbon steel specimens with weight percentage composition as follows; C-0.05; Mn-0.6; P-0.36; Si-0.3 and the balance Fe. The blank corrodents were respectively $1.0 \mathrm{M} \mathrm{HCl}$ and $0.5 \mathrm{M} \mathrm{H}_{2} \mathrm{SO}_{4}$ solutions. Stock solutions of $\mathrm{AD}$ extract were prepared by boiling $20 \mathrm{~g}$ of the dried and ground leaves under reflux for $3 \mathrm{~h}$ in $1.0 \mathrm{M} \mathrm{HCl}$ and $0.5 \mathrm{M} \mathrm{H}_{2} \mathrm{SO}_{4}$ solutions, respectively. The resulting solutions were cooled then triple filtered. The amount of material extracted into solution was quantified by comparing the weight of the dried residue with the initial weight of the dried plant material before extraction. Inhibitor test solutions were prepared in the concentration range 100-1000 $\mathrm{mg} / \mathrm{L}$ from the respective stock solutions. 


\section{Gravimetric experiments}

Gravimetric experiments were conducted on test coupons of dimension $3 \mathrm{~cm}$ x 3 $\mathrm{cm} \times 0.14 \mathrm{~cm}$. These coupons were wet-polished with silicon carbide abrasive paper (from grade \#400 to \#1000), rinsed with distilled water, and dried in acetone and warm air, weighed and stored in a moisture-free desiccator prior to use. The pre-cleaned and weighed coupons were subsequently suspended in beakers containing the test solutions using glass hooks and rods. Tests were conducted under total immersion conditions in $300 \mathrm{~mL}$ of the aerated and unstirred test solutions. To determine the weight loss, coupons were retrieved from test solutions after $6 \mathrm{~h}$, appropriately cleaned, dried and re-weighed. The weight loss was taken to be the difference between the initial and final weights of the coupons. All tests were run in triplicate and the data showed good reproducibility. Average values for each experiment were obtained and used in subsequent calculations.

\section{Electrochemical measurements}

Test metal samples for electrochemical experiments were machined into rectangular specimens and fixed in polytetrafluoroethylene (PTFE) rods by epoxy resin in such a way that only one surface of area $1 \mathrm{~cm}^{2}$ was left uncovered. The exposed surface was also cleaned as described above. Electrochemical experiments were conducted in a three-electrode corrosion cell using a VERSASTAT 400 Complete DC Voltammetry and Corrosion System, with V3 Studio software. A graphite rod was used as counter electrode and a saturated calomel electrode (SCE) as reference electrode. The latter was connected via a Luggin's capillary. Measurements were performed in aerated and unstirred solutions at the end of $1 \mathrm{~h}$ of immersion at $30 \pm 1{ }^{\circ} \mathrm{C}$. Impedance measurements were made at corrosion potentials $\left(\mathrm{E}_{\text {corr }}\right)$ over a frequency range of $100 \mathrm{kHz}-10$ $\mathrm{mHz}$, with a signal amplitude perturbation of $5 \mathrm{mV}$. Potentiodynamic polarization studies were carried out in the potential range $\pm 250 \mathrm{mV}$ versus corrosion potential at a scan rate of $0.333 \mathrm{mV} \mathrm{s}^{-1}$. Each test was run in triplicate to verify the reproducibility of the data.

All theoretical calculations were performed using the DFT electronic structure programs Forcite and $\mathrm{DMol}^{3}$ as contained in the Materials Studio 4.0 software.

\section{Results and discussion}

\section{Weight losses and corrosion rates}

The anodic dissolution of iron in acidic solutions is known to proceed via a hydroxyl ion catalyzed mechanism [23]:

$$
\begin{gathered}
\mathrm{Fe}+\mathrm{OH}^{-} \rightarrow \cdot \mathrm{FeOH}_{\mathrm{ads}}+\mathrm{H}^{+}+\mathrm{e} \\
\mathrm{FeOH}_{\mathrm{ads}} \rightarrow \mathrm{FeOH}++\mathrm{e} \\
\mathrm{FeOH}^{+}+\mathrm{H}^{+} \rightarrow \mathrm{Fe}^{2+}+\mathrm{H}_{2} \mathrm{O}
\end{gathered}
$$


As a consequence of these reactions, including the high solubility of the corrosion products, the metal loses weight in the solution. The corrosion rates of the mild steel test coupons in $1 \mathrm{M} \mathrm{HCl}$ and $0.5 \mathrm{M} \mathrm{H}_{2} \mathrm{SO}_{4}$ in the absence and presence of $\mathrm{AD}$ extract were therefore assessed by weight loss measurements. Fig. 1 shows the corrosion rates of the mild steel coupons in $1 \mathrm{M} \mathrm{HCl}$ and $0.5 \mathrm{M}$ $\mathrm{H}_{2} \mathrm{SO}_{4}$ without and with different concentrations of AD. The data presented are means of triplicate determinations, with standard deviation ranging from 0 0.00054. The fact that the metal specimen manifests higher corrosion susceptibility in $0.5 \mathrm{M} \mathrm{H}_{2} \mathrm{SO}_{4}$ is evidence that the acid anions influence the corrosion process in different ways. The lower corrosion rates of the metal specimens in $1 \mathrm{M} \mathrm{HCl}$ is attributable to the ability of chloride ions to replace hydroxyl ions adsorbed on the metal surface, thus reducing the catalytic effect. Fig. 1 also clearly reveals a general reduction in corrosion rates in both $1 \mathrm{M} \mathrm{HCl}$ and $0.5 \mathrm{M} \mathrm{H}_{2} \mathrm{SO}_{4}$ due to $\mathrm{AD}$ addition, suggesting a corrosion inhibiting effect of the extract. The inhibiting effect becomes more pronounced with increasing AD concentration, implying a dependence of the inhibition process on the amount of inhibiting species present in the system.

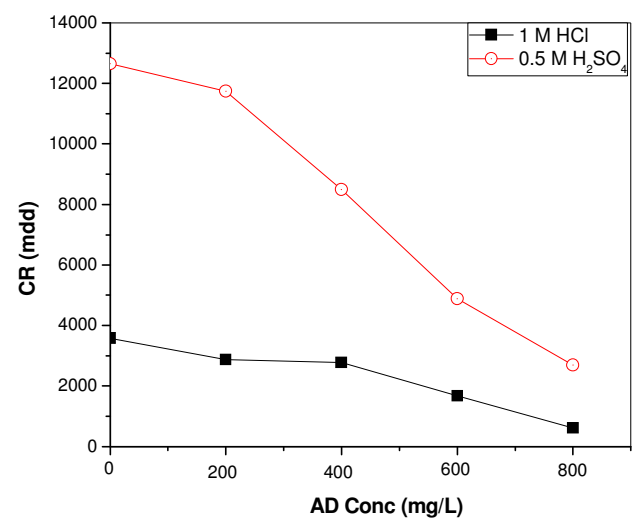

Figure 1. Weight loss of carbon steel $1 \mathrm{M} \mathrm{HCl}$ and $0.5 \mathrm{M} \mathrm{H}_{2} \mathrm{SO}_{4}$ without and with different concentrations of $\mathrm{AD}$ extract.

Quantitative characterization of the effect of AD extract on the free corrosion of mild steel in the different acid solutions was carried out by an assessment of the inhibition efficiency $(\eta \%)$, obtained by comparing the corrosion rates in the absence $\left(\mathrm{CR}_{\text {blank }}\right)$ and presence $\left(\mathrm{CR}_{\mathrm{inh}}\right)$ of $\mathrm{AD}$ extract using the equation:

$$
\eta \%=\left(1-\frac{C R_{\text {inh }}}{C R_{\text {blank }}}\right) \times 100
$$

Fig. 2 shows the obtained $\eta \%$ values at different $\mathrm{AD}$ concentration in $1 \mathrm{M} \mathrm{HCl}$ and $0.5 \mathrm{M} \mathrm{H}_{2} \mathrm{SO}_{4}$. Efficiency is actually comparable in both acid media and generally increased with AD concentration. 


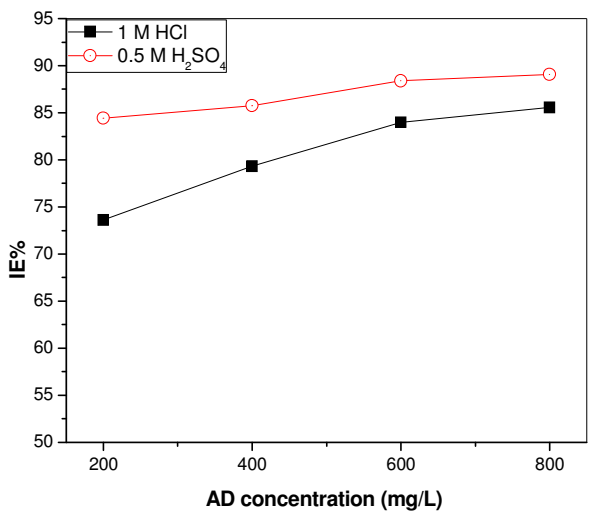

Figure 2. Inhibition efficiency of $\mathrm{AD}$ extract in $1 \mathrm{M} \mathrm{HCl}$ and $0.5 \mathrm{M} \mathrm{H}_{2} \mathrm{SO}_{4}$.

The protective action of biomass extracts is often attributed to their phytochemical constituents, with molecular and electronic structures similar to organic corrosion inhibitors. Organic inhibitors function by adsorption on the corroding metal surface and subsequent displacement of pre-adsorbed water molecules.

$$
\mathrm{Inh}_{(\mathrm{sol})}+x \mathrm{H}_{2} \mathrm{O}_{(\mathrm{ads})} \rightarrow \operatorname{Inh}_{(\mathrm{ads})}+x \mathrm{H}_{2} \mathrm{O}_{(\mathrm{sol})}
$$

The resulting adsorption film then isolates the metal surface from the corrosive medium to an extent depending on the degree of the surface coverage. The observed increase in inhibition efficiency with $\mathrm{AD}$ concentration thus results from increased adsorption of the extract organic matter on the mild steel surface, thereby reducing the surface area available for the corrosion reaction. The proposed adsorption of the extract constituents is substantiated by the data fit to the Langmuir adsorption isotherm, as depicted in Fig. 3.

\section{Electrochemical measurements}

Since corrosion is an electrochemical process, electrochemical techniques are best suited for mechanistic studies of corrosion systems. Polarization measurements are particularly appropriate for monitoring the progress and mechanisms of the anodic and cathodic partial reactions as well as identifying the effect of an additive on the cathodic and anodic partial reactions, whereas impedance measurements provide insight into the corrosion mechanism at the metal/corrodent interface in absence and presence at additives. Measurements were therefore also undertaken to understudy the inhibiting effect of AD from an electrochemical perspective in order to gain insights into the electrochemical mechanisms of the corrosion inhibition process. The highest concentration of AD studied $(800 \mathrm{mg} / \mathrm{L})$ was chosen for the electrochemical measurements. 


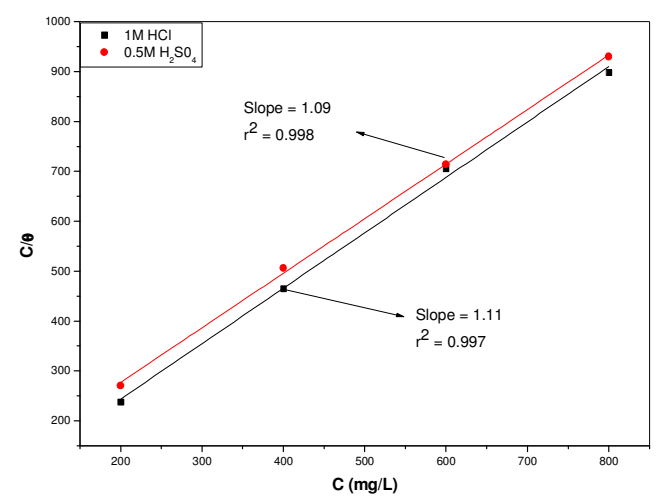

Figure 3. Langmuir isotherm for $\mathrm{AD}$ extract adsorption on mild steel in $1 \mathrm{M} \mathrm{HCl}$ and $0.5 \mathrm{M} \mathrm{H}_{2} \mathrm{SO}_{4}$.

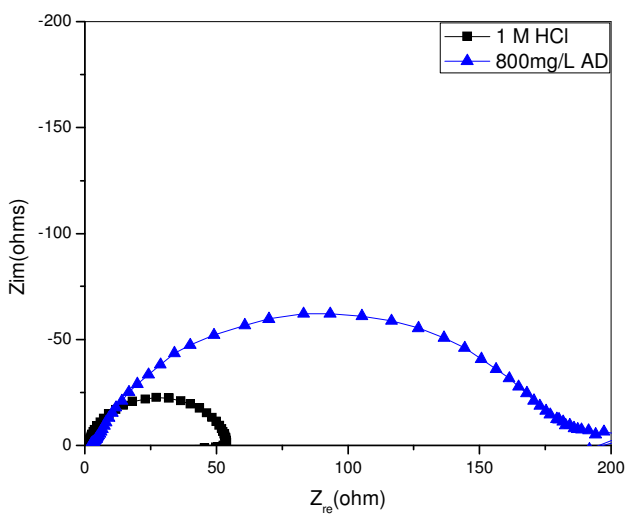

Figure 4. Effect of AD extract on the impedance behaviour of mild steel in $1 \mathrm{M} \mathrm{HCl}$.

\section{Electrochemical impedance spectroscopy}

Impedance experiments were undertaken to afford insight into the characteristics and kinetics of electrochemical processes occurring at the mild steel/1 $\mathrm{M} \mathrm{HCl}$ and mild steel/0.5 $\mathrm{M} \mathrm{H}_{2} \mathrm{SO}_{4}$ interfaces in absence and presence of $\mathrm{AD}$. The impedance responses of these systems are presented as Nyquist plots in Fig. 4 and Fig. 5, respectively. The Nyquist plots show single depressed semicircles for all systems over the frequency range studied. The observed depression of the Nyquist semicircle with center under the real axis is typical for solid metal electrodes that show frequency dispersion of the impedance data. The high frequency intercept with the real axis in the Nyquist plots is assigned to the solution resistance $\left(R_{s}\right)$ and the low frequency intercept with the real axis ascribed to the charge transfer resistance $\left(R_{c t}\right)$. The impedance spectra were analyzed by fitting to the equivalent circuit model in Fig. $6\left[\mathrm{R}_{\mathrm{s}}\left(\mathrm{Q}_{\mathrm{dl}} \mathrm{R}_{\mathrm{ct}}\right)\right]$, which has been used previously to adequately model the mild steel/acid interface [2425]. In this equivalent circuit, the solution resistance is shorted by a constant phase element (CPE) that is placed in parallel to the charge transfer resistance. The CPE is used in place of a capacitor to compensate for deviations from ideal dielectric behavior arising from the inhomogeneous nature of the electrode surfaces. The impedance of the CPE is given by [24]: 


$$
\mathrm{Z}_{\mathrm{CPE}}=\mathrm{Q}^{-1}(\mathrm{j} \omega)^{-\mathrm{n}}
$$

where $\mathrm{Q}$ and $\mathrm{n}$ stand for the CPE constant and exponent respectively, $\mathrm{j}=(-1)^{1 / 2}$ is an imaginary number, $\omega$ is the angular frequency in $\operatorname{rad~s}^{-1},(\omega=2 \pi f)$ when $\mathrm{f}$ is the frequency in $\mathrm{Hz}$.

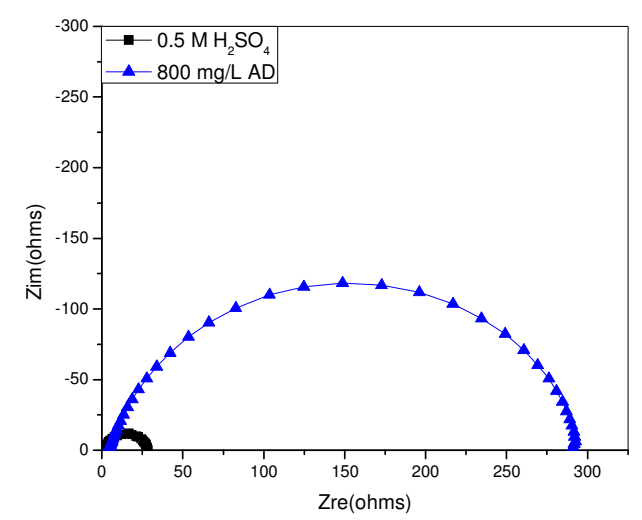

Figure 5. Effect of $\mathrm{AD}$ extract on the impedance behaviour of mild steel in $0.5 \mathrm{M}$ $\mathrm{H}_{2} \mathrm{SO}_{4}$.

Addition of AD increased $\mathrm{R}_{\mathrm{ct}}$ values from $52.8 \Omega-\mathrm{cm}^{2}$ to $192.7 \Omega-\mathrm{cm}^{2}$ in $1 \mathrm{M}$ $\mathrm{HCl}$ and from $32.9 \Omega-\mathrm{cm}^{2}$ to $286.3 \Omega-\mathrm{cm}^{2}$ in $0.5 \mathrm{M} \mathrm{H}_{2} \mathrm{SO}_{4}$. Such enhancement of $\mathrm{R}_{\mathrm{ct}}$ corresponds to an increase in the diameter of the Nyquist semicircle, confirming the corrosion inhibiting effect of the extract. Inhibition efficiency from the impedance data $\left(\eta_{\mathrm{R}} \%\right)$ was estimated by comparing the values of the charge transfer resistance in the absence $\left(\mathrm{R}_{\mathrm{ct}, \mathrm{bl}}\right)$ and presence of inhibitor $\left(\mathrm{R}_{\mathrm{ct}, \mathrm{inh}}\right)$ as follows:

$$
\eta_{R} \%=\left(\frac{R_{c t \text { (inh) }}-R_{c t}}{R_{c t \text { (inh) }}}\right) \times 100
$$

The obtained values are $72.6 \%$ (in $1 \mathrm{M} \mathrm{HCl}$ ) and $88.7 \%\left(0.5 \mathrm{M} \mathrm{H}_{2} \mathrm{SO}_{4}\right)$.

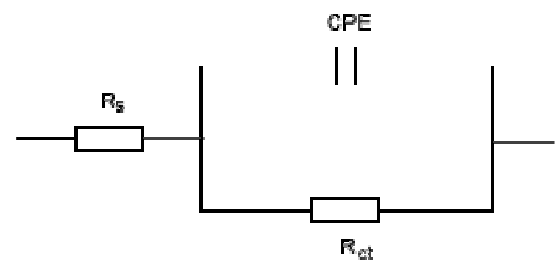

Figure 6. The electrochemical equivalent circuit used to fit the impedance spectra: Rs = solution resistance, $\mathrm{Rct}=$ charge transfer resistance, $\mathrm{CPE}=$ constant phase element.

The values of the double layer capacitance $\left(\mathrm{C}_{\mathrm{dl}}\right)$, obtained at the frequency wherein the imaginary component of the impedance is a maximum $\left(-Z_{i m, \max }\right)$ according to Eq. (8) were also modified by the extract, decreasing from 39.4 $\mu \mathrm{Fcm}^{-2}$ to $14.4 \mu \mathrm{Fcm}^{-2}$ in $1 \mathrm{M} \mathrm{HCl}$ and from $37.6 \mu \mathrm{Fcm}^{-2}$ to $10.7 \mu \mathrm{Fcm}^{-2}$ in $0.5 \mathrm{M}$ $\mathrm{H}_{2} \mathrm{SO}_{4}$. 


$$
f\left(-Z_{i m, \max }\right)=\frac{1}{2 \pi C_{d l} R_{t}}
$$

Such reduction, according to the Helmholtz model (Eq. 9), normally results from a decrease in the dielectric constant $(\varepsilon)$ or an increase in the double layer thickness $(\delta)$ due to species adsorption at the double layer:

$$
\mathrm{C}_{\mathrm{dl}}=\varepsilon \varepsilon_{\mathrm{o}} \mathrm{A} / \delta
$$

where $\varepsilon_{\mathrm{o}}$ is the vacuum permittivity and $\mathrm{A}$ is the electrode. Since adsorption of an organic inhibitor on a metal surface involves the replacement of water molecules pre-adsorbed on the surface, the smaller dielectric constant of organics compared to water as well as the increased thickness of the double layer due to inhibitor adsorption act simultaneously to reduce the interfacial capacitance. This provides experimental evidence of adsorption of the extract organic matter on the corroding mild steel surface.

\section{Potentiodynamic polarization}

Potentiodynamic polarization experiments were undertaken in order to gain some mechanistic insight on the effect of $\mathrm{AD}$ on the anodic and cathodic reactions of mild steel in both environments. The resulting polarization curves in $1 \mathrm{M} \mathrm{HCl}$ and $0.5 \mathrm{M} \mathrm{H}_{2} \mathrm{SO}_{4}$ are given in Fig. 7 and Fig. 8, respectively. Again the net effect of $\mathrm{AD}$ extract on the corrosion process in both environments appears quite similar as the anodic and cathodic reactions are inhibited, while $\mathrm{E}_{\text {corr }}$ was not altered to any significant extent. This implies that the corrosion inhibition process is under mixed control. A closer look at the polarization curves however reveals that the cathodic inhibiting effect was more pronounced in $1 \mathrm{M} \mathrm{HCl}$, where the extract reduced the corrosion current $\left(\mathrm{i}_{\text {corr }}\right)$ from $2184 \mu \mathrm{A} \mathrm{cm}^{-2}$ to 399.3 $\mu \mathrm{A} \mathrm{cm}{ }^{-2}$ while the anodic inhibiting effect was more prominent in $0.5 \mathrm{M} \mathrm{H}_{2} \mathrm{SO}_{4}$, with a corresponding decrease in $\mathrm{i}_{\text {corr }}$ from $2388 \mu \mathrm{A} \mathrm{cm}^{-2}$ to $339.1 \mu \mathrm{A} \mathrm{cm}^{-2}$.

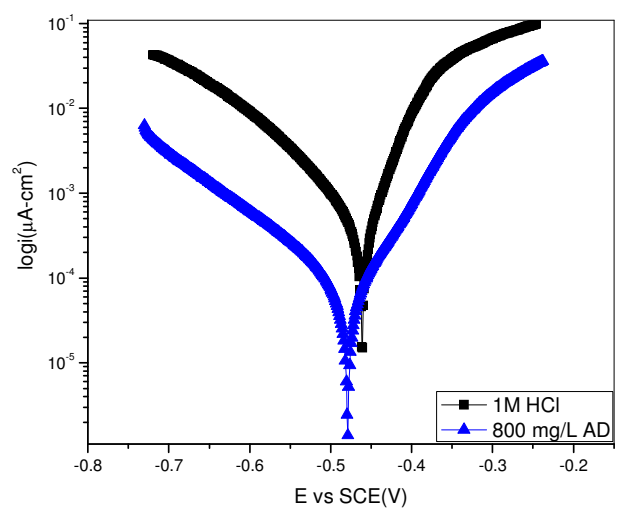

Figure 7. Effect of AD extract on the potentiodynamic polarization behaviour of mild steel in $1 \mathrm{M} \mathrm{HCl}$. 


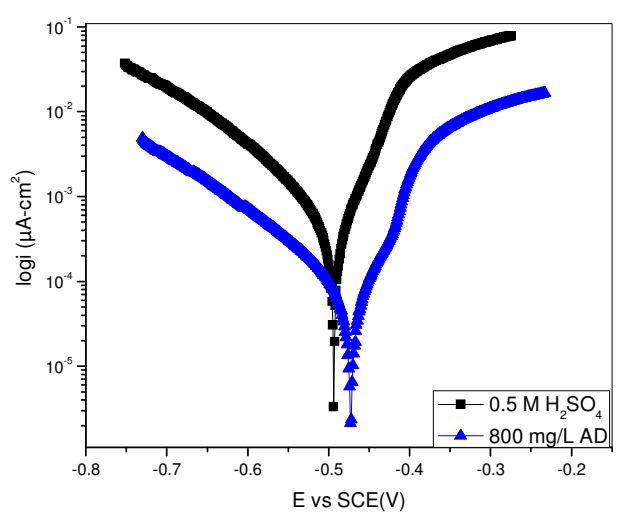

Figure 8. Effect of AD extract on the potentiodynamic polarization behaviour of mild steel in $0.5 \mathrm{M} \mathrm{H}_{2} \mathrm{SO}_{4}$.

The values of the corrosion current density in the absence $\left(\mathrm{i}_{\text {corr,bl }}\right)$ and presence of the inhibitor $\left(\mathrm{i}_{\text {corr,inh }}\right)$ were used to estimate the inhibition efficiency from polarization data $\left(\eta_{\mathrm{i}} \%\right)$ as follows:

$$
\eta_{i} \%=\left(1-\frac{i_{c o r r, i n h}}{i_{c o r r, b l}}\right) \times 100
$$

The calculated values were $81.7 \%$ and $85.8 \%$ in $1 \mathrm{M} \mathrm{HCl}$ and $0.5 \mathrm{M} \mathrm{H}_{2} \mathrm{SO}_{4}$ respectively.

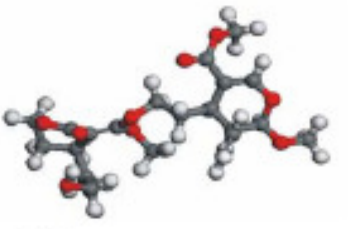

(a)

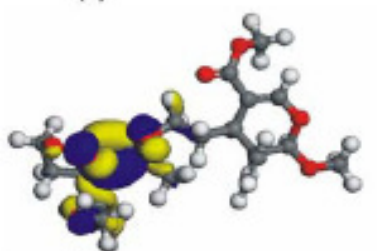

(c)

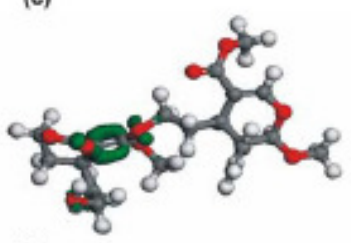

(e)

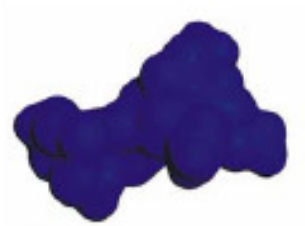

(b)
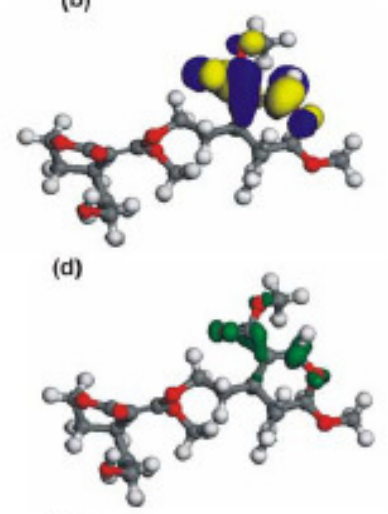

(f)

Figure 9. Electronic structure model of DJN: (a) optimized structure; (b) total electron density; (c) HOMO orbital; (d) LUMO orbital; (e) electrophilic Fukui function (f); (f) nucleophilic Fukui function $\left(\mathrm{f}^{+}\right)$. [Atom legend: white $=\mathrm{H}$; gray $=\mathrm{C}$; red $=\mathrm{O}$. The blue and yellow isosurfaces depict the electron density difference; the blue regions show electron accumulation, while the yellow regions show electron loss. The green isosurfaces describe the Fukui functions] (COLOUR ONLINE). 


\section{Theoretical considerations}

As it is often the case with biomass extracts, the multi component nature of AD extract makes it rather difficult to ascribe the observed inhibiting effect to any particular constituents. Nevertheless, since corrosion inhibiting action is often linked with the presence of polar heteroatoms, pi-bond conjugation, aromaticity, electron delocalization regions, etc., it is possible to qualitatively predict the adsorption behaviour of extract components having chemical structures similar to those of conventional organic molecules with previously established efficacy. Based on this consideration, the chemical structures of djalonenoside (DJN) and its $\mathrm{HCl} / \mathrm{MeOH}$ hydrolysis product DJN-hyd recommend them for theoretical assessment of corrosion inhibiting potential. The quantum chemical computations are not necessarily intended to provide detailed description of the adsorption of the extract. Instead, the idea is to recognize the relative contributions of the different extract components through their individual adsorption strengths and mechanisms.

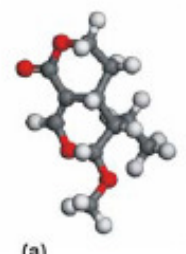

(a)
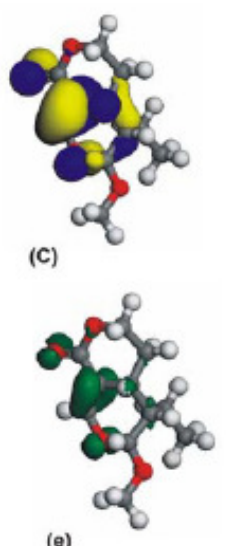

(e)

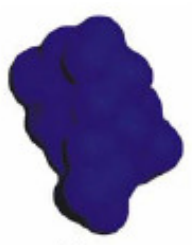

(b)
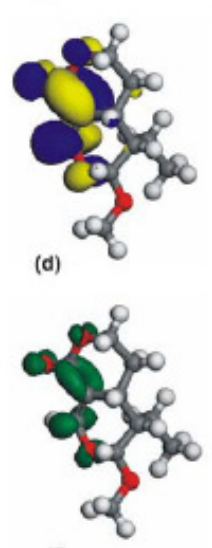

(f)

Figure 10. Electronic structure model of DJN-hyd: (a) optimized structure; (b) total electron density; (c) HOMO orbital; (d) LUMO orbital; (e) electrophilic Fukui function (f); (f) nucleophilic Fukui function $\left(\mathrm{f}^{+}\right)$. [Atom legend: white $=\mathrm{H}$; gray $=\mathrm{C}$; red $=\mathrm{O}$. The blue and yellow isosurfaces depict the electron density difference; the blue regions show electron accumulation, while the yellow regions show electron loss. The green isosurfaces describe the Fukui functions] (COLOUR ONLINE).

DFT-based quantum chemical computations were undertaken to model the electronic and adsorption structures of DJN and DJN-hyd. The calculations were performed by means of the DFT electronic structure program $\mathrm{DMol}^{3}$ using a Mulliken population analysis [26,27]. Electronic parameters for the simulation include restricted spin polarization using the DND basis set and the Perdew Wang (PW) local correlation density functional. The molecular structures were first subjected to geometry optimization using COMPASS force field and the 
Smart minimize method by high-convergence criteria and then the distribution of frontier molecular orbitals including the highest occupied molecular orbital (HOMO) and the lowest unoccupied molecular orbital (LUMO) determined. The HOMO regions are the sites at which electrophiles attack and represent the active centers, with the utmost ability to bond to the metal surface, whereas the LUMO orbital can accept the electrons from the d-orbital of the metal (Fe) using antibonding orbitals to form feedback bonds [28-31]. The local reactivity of the molecules was analyzed by means of the Fukui indices (FI) to assess reactive regions in terms of nucleophilic $\left(\mathrm{f}^{+}\right)$and electrophilic attack $\left(\mathrm{f}^{-}\right)$.

Table 1. HOMO and LUMO energies of DJN and DJN-hyd.

\begin{tabular}{lcc}
\hline Property & DJN & DJN-hyd \\
\hline $\mathrm{E}_{\text {HOMO }}(\mathrm{eV})$ & -5.805 & -5.188 \\
$\mathrm{E}_{\mathrm{LUMO}}(\mathrm{eV})$ & -1.883 & -2.102 \\
$\mathrm{E}_{\mathrm{LUMO}-\mathrm{HOMO}}$ & 3.922 & 3.086 \\
\hline
\end{tabular}

The model structures are presented in Figs. 9 and 10 for DJN and DJN-hyd respectively. Table 1 provides some quantum-chemical parameters related to the molecular electronic structure of the most stable conformation of the molecules. High values of the HOMO energy $\left(\mathrm{E}_{\mathrm{HOMO}}\right)$ indicate a tendency of the molecule to donate electrons to an appropriate acceptor molecule with low energy or an empty electron orbital, in this case vacancies in the $3 \mathrm{~d}$ orbital of the Fe atom. The energy of the LUMO characterizes the susceptibility of molecules towards nucleophilic attack [31-36]. Low values of the energy of the gap $\Delta \mathrm{E}=\mathrm{E}_{\text {LUMO- }}$ номо imply that the energy to remove an electron from the last occupied orbital will be minimized, corresponding to improved inhibition efficiencies.
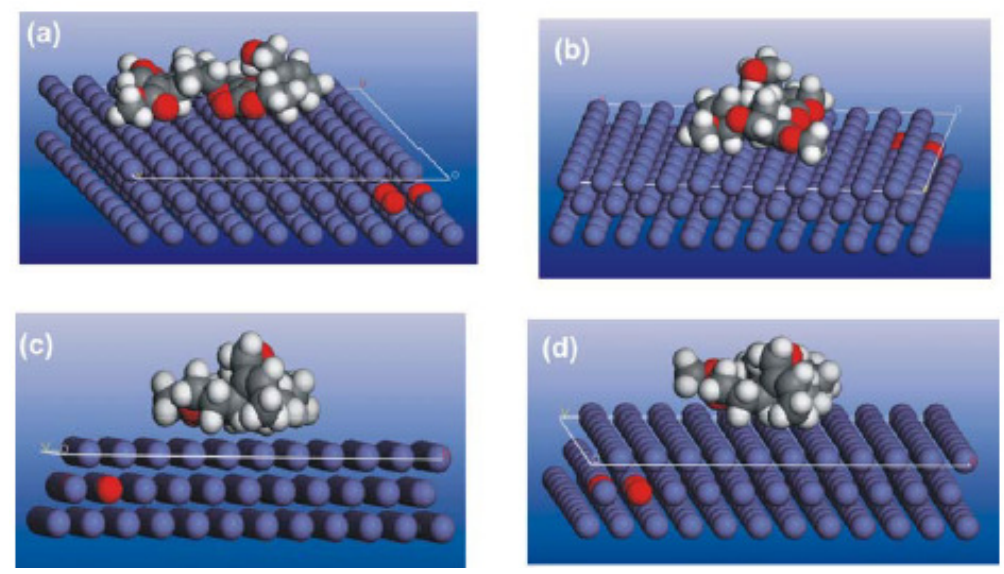

Figure 11. Molecular dynamics model of the adsorption of a single molecule of DJN on Fe (110) surface: on-top views $(a, b)$; side views $(c, d)$.

The local reactivity of the molecules as assessed from the Fukui indices (FI) shows that the f sites for all the molecules correspond with the HOMO locations, while the $\mathrm{f}^{+}$sites correspond with the LUMO locations, indicating the zones 
through which the molecule would likely interact with the Fe surface. The $\mathrm{E}_{\mathrm{HOMO}}$, $\mathrm{E}_{\mathrm{LUMO}}$ and $\Delta \mathrm{E}$ values do not vary very significantly for DJN and DJN-hyd, which means that any observed differences in their adsorption strengths would result from molecular size parameters rather than from electronic structure parameters. The seemingly high values of $\Delta \mathrm{E}(>3 \mathrm{eV})$ suggest a dearth of electron transfer processes in the interaction of the molecules with the metal surface.
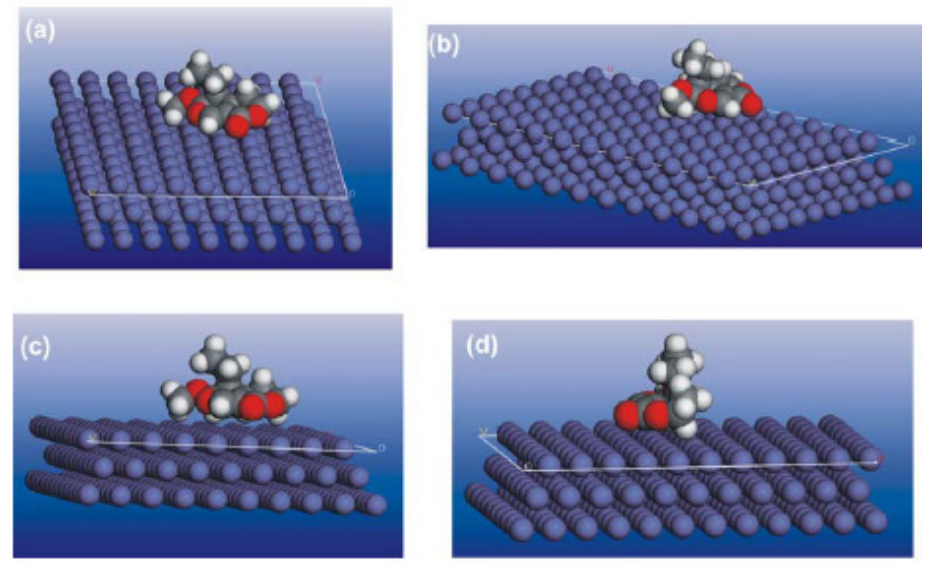

Figure 12. Molecular dynamics model of the adsorption of a single molecule of DJNhyd on Fe (110) surface: on-top views (a,b); side views (c,d).

Molecular dynamics (MD) simulations were undetaken to model the adsorption of the molecules on the metal surface at a molecular level. This was achieved using Forcite quench molecular dynamics in the MS Modeling 4.0 software to sample many different low energy configurations and identify the low energy minima [37,38]. Optimized structures of DJN and DJN-hyd and the Fe surface were used for the simulation. Calculations were carried out in an 11 x 9 supercell using the COMPASS force field and the Smart algorithm. The Fe crystal was cleaved along the (110) plane. Temperature was fixed at $350 \mathrm{~K}$, with NVE (microcanonical) ensemble. The time step was $1 \mathrm{fs}$ and simulation time $5 \mathrm{ps}$. The system was quenched every 250 steps. The optimized (lowest energy) adsorption models for single molecules of DJN and DJN-hyd respectively on the Fe (110) surface from our simulation are shown in Figs. 11 and 12. The molecules can be seen to maintain a flat-lying adsorption orientation on the Fe surface, with the regions of high HOMO density acting as the adsorption sites. Using the quench molecular dynamics method above, we calculated the binding energy $\left(\mathrm{E}_{\mathrm{Bind}}\right)$ of each molecule on the Fe surface using the following equation:

$$
\mathrm{E}_{\mathrm{Bind}}=\mathrm{E}_{\mathrm{total}}-\left(\mathrm{E}_{\mathrm{Mol}}+\mathrm{E}_{\mathrm{Fe}}\right)
$$

$\mathrm{E}_{\mathrm{Mol}}, \mathrm{E}_{\mathrm{Fe}}$ and $\mathrm{E}_{\mathrm{total}}$ correspond respectively to the total energies of the molecule, Fe (110) slab and the adsorbed Mol/Fe (110) couple. In each case the potential energies were calculated by averaging the energies of the five structures of lowest energy, and a negative value of $\mathrm{E}_{\mathrm{ads}}$ corresponds to a stable adsorption structure. The obtained values of the binding energy were $-190 \mathrm{kcal} / \mathrm{mol}$ and $99.1 \mathrm{kcal} / \mathrm{mol}$ for DJN and DJN-hyd, respectively. The higher stability of the adsorbed DJN compared with DJN-hyd is attributable to the larger size of the 
DJN molecule, which makes a greater contribution to the observed inhibiting effect of AD extract.

\section{Conclusion}

The Anthocleista djalonesis extract inhibited mild steel corrosion in $1 \mathrm{M} \mathrm{HCl}$ and $0.5 \mathrm{M} \mathrm{H}_{2} \mathrm{SO}_{4}$ solutions. The inhibition efficiency was found to increase with increased inhibitor concentration. Impedance results revealed that the extract functioned via adsorption of the organic matter on the metal/solution interface. Polarization measurements show that the adsorbed organic matter extract inhibited the corrosion process via mixed-inhibition mechanism, affecting both the anodic metal dissolution reaction and the cathodic hydrogen evolution reaction. DFT based quantum chemical computations of parameters associated with the electronic structures of two components of the extract, djalonenoside (DJN) and its hydrolysis product DJN-hyd, confirmed their inhibiting potential, which was further corroborated by molecular dynamics modeling of the adsorption of the single molecules on the metal surface.

\section{Acknowledgements}

This project is supported by TWAS, the Academy of Sciences for the developing World, under the TWAS Grants for Research Units in Developing Countries Program (TWAS-RGA08-005) and the Education Trust Fund (ETF); under batch one of ETF 2009/2010 research projects intervention for the Federal University of Technology Owerri.

\section{References}

1. Gunasekaran G, Chauhan LR. Electrochim Acta. 2004;49:4387.

2. El-Etre AY. Corros Sci. 2003;45:2485.

3. Abdallah M. Corros Sci. 2004;46:1981.

4. Li Y, Zhao P, Liaqng Q, Hou B. Appl Surf Sci. 2005;252:1245.

5. El-Etre AY, Abdallah M, El-Tantawy ZE. Corros Sci. 2005;47:385.

6. Chauhan LR, Gunasekaran G. Corros Sci. 2007;49:1143.

7. Raja PB, Sethuraman M, Mater Lett. 2008;62:2922.

8. Oguzie EE. Corros Sci. 2008;50:2993.

9. Okafor PC, Ikpi ME, Uwah IE, Ebenso EE, Ekpe UJ, Umoren SA. Corros Sci. 2008;50:2310.

10. Abdel-Gaber AM, Abd-El-Nabey BA, Sidahmed IM, El-Zayady AM, Saadawy M. Corros Sci. 2006;48:2765.

11. Moretti G, Guidi F, Grion G. Corros Sci. 2004;46:387.

12. Oguzie EE, Port Electrochim Acta. 2008;26:303.

13. Rosliza R, Wan Nik WB. Curr Appl Phys. 2010;10:221.

14. Abiola OK, James AO. Corros Sci. 2010;52:661.

15. Oguzie EE, Onuchukwu AI, Corros Rev. 2007;25:355.

16. Ostovari A, Hoseinieh SM, Peikari M, Shadizadeh SR, Hashemi SJ. Corros Sci. 2009;51:1935. 
17. Satapathy AK, Gunasekaran G, Sahoo SC, Amit K, Rodrigues PV. Corros Sci. 2009;51:2848.

18. Cardozo da Rocha J, Gomes JCP, D’Elia E. Corros Sci. 2010;52:2341.

19. Okafor PC, Ikpi ME, Uwah IE, Ebenso EE, Ekpe UJ, Umoren SA. Corros Sci. 2008;50:2310.

20. Oguzie EE, Enenebeaku CK, Akalezi CO, Okoro SC, Ayuk AA, Ejike EN, J Colloid Interface Sci. 2010;349:283.

21. Okwu DE, Ighodaro BU. Int J Drug Dev Res. 2009;1:117.

22. Obame LC, Edou P, Bassole HN, Koudou J, Agnaniet A, Eba F, Traore AS. African J Microbiol Res. 2008;2:148.

23. Bockris JO'M, Drazic D. Electrochim Acta. 1962;7:293.

24. Popova A, Sokolova E, Raicheva S, Christov M. Corros Sci. 2003;45:33.

25. Khaled KF, Hackerman N, Electrochim Acta. 2003;48:2715.

26. Delley B. J Chem Phys. 1990;92:508.

27. Delley B. J Chem Phys. 2000;113:7756.

28. Martinez S, Stagljar I. Theochem. 2003;640:167.

29. Khaled KF, Babic-Samardzija K, Hackerman N, Electrochim Acta. 2005;50:2515.

30. Cruz J, Garcia-Ochoa E, Castro M, J Electrochem Soc. 2003;150:26.

31. Obot IB, Obi-Egbedi NO, Corros Sci. 2010;52:198.

32. Fu J, Li S, Wang Y, Cao L, Lu L, J Mater Sci. 2010;45:6255.

33. Rodriguez-Valdez LM, Villamisar W, Casales M, Gonzalez-Rodriguez JG, Martınez-Villafane A, Martinez L, Glossman-Mitnik D, Corros Sci. 2006;48:4053.

34. Gece G, Corros Sci. 2008;52:2981.

35. Gece G, Bilgic S. Corros Sci. 2010;52:3435.

36. Oguzie EE, Wang SG, Li Y, Wang FH, J Phys Chem C. 2009;113:8420.

37. Casewit CJ, Colwell KS, Rappé AK, J Am Chem Soc. 1992;114:10035.

38. Casewit CJ, Colwell KS, Rappé AK, J Am Chem Soc. 1992;114:10046. 